\title{
Métodos e Parâmetros para Estudo da Vegetação com Ênfase no Estrato Arbóreo
}

\author{
Welington Kiffer de Freitas ${ }^{1}$, Luís Mauro Sampaio Magalhães ${ }^{2}$ \\ ${ }^{1}$ Pós-graduação em Ciências Ambientais e Florestais, Instituto de Florestas - IF, \\ Universidade Federal Rural do Rio de Janeiro - UFRRJ, Rio de Janeiro/RJ, Brasil \\ ${ }^{2}$ Departamento de Ciências Ambientais, Instituto de Florestas - IF, \\ Universidade Federal Rural do Rio de Janeiro - UFRRJ, Seropédica/RJ, Brasil
}

\begin{abstract}
RESUMO
Levantamentos da estrutura e da composição florística de comunidades vegetais, em especial de fragmentos florestais, têm se intensificado nas últimas décadas. As informações obtidas nestas atividades servem de base para a proteção e a recuperação destas formações. Um conjunto de métodos tem sido aplicado nestes levantamentos e este artigo visa a elencar, atualizar e discutir estes métodos, indicando também os diferentes parâmetros que têm sido estudados, no sentido de se acumular um conhecimento suficiente para o manejo adequado, principalmente de florestas remanescentes. Não obstante o esforço dos últimos anos, as informações disponíveis ainda estão aquém das necessidades dos gestores que precisam intervir nestes sistemas.
\end{abstract}

Palavras-chave: levantamento fitossociológico, ecologia vegetal, levantamento da vegetação.

\section{Methods and Parameters for Plant Survey with Emphasis on Arboreal Stratum}

\begin{abstract}
Researches on the structure and floristic composition of plant communities, especially forest fragments, have intensified in recent decades. Information obtained from these activities is the basis for the protection and rehabilitation of these communities. A set of methods have been applied in these surveys. This article aims to list and discuss these methods indicating the different parameters studied, in order to accumulate sufficient knowledge for proper management, particularly in the forest remnants. Even with all the efforts made recently, the information available is still below the needs required by managers to intervene in these systems.
\end{abstract}

Keywords: phytosociological survey, plant ecology, plant survey.

\section{INTRODUÇÃO}

As primeiras pesquisas abordando as comunidades de plantas e a sua organização surgiram por volta do século XIX, por meio de iniciativas de pesquisadores, como Johann Baptist Emanuel Pohl, Johannes Eugenius Bülow Warming e Alexander von Humboldt, dentre outros, que foram também os precursores no reconhecimento de grupos de plantas como "unidades de estudo" (IBGE, 1992; Trimer, 2010).

A partir de então, as comunidades vegetais começaram a ganhar destaque, considerando-se a sua utilidade na identificação e na definição dos limites 
de ecossistemas (Mueller-Dombois \& Ellenberg, 1974; Matteucci \& Colma, 1982). Estas abordagens foram evoluindo e os pesquisadores perceberam que os estudos deveriam avançar para uma análise mais acurada sobre a composição florística (Lorenzini, 2006).

Conforme Whittaker (1962 apud Iserhagen et al., 2011), a necessidade de se avançar na compreensão dos recursos florísticos originou diferentes linhas de pensamento, representadas principalmente pelas escolas de Zurique-Montpellier (Braun-Blanquet), sueca (Du Rietz), russa (Ramenski e Sukatschew), inglesa (Tansley) e norte-americana (Clements e Gleason). As três primeiras apresentavam uma abordagem mais estática e as demais buscavam enfocar uma dinâmica temporal da vegetação.

Nos métodos de classificação, relacionados à escola de Zürich-Montpellier e ao método "relevé", o objetivo é a descrição de uma comunidade, ou associação, segundo o conceito original, em termos principalmente florísticos, visando a determinar a área mínima necessária para representar a comunidade. Nesse caso, a presença ou a ausência de espécies é mais importante do que as variações nos aspectos quantitativos (Schilling \& Batista, 2008).

Na Suécia, território com maior homogeneidade da cobertura vegetal, a dominância de espécies assumiu papel de destaque. Os estudos mostravam que comunidades estáveis, de composição florística homogênea, formavam sistemas complexos, com grupamentos de espécies "dominantes" podendo ser encontrados no mesmo habitat (Iserhagenet al., 2011).

$\mathrm{Na}$ escola russa, tornou-se comum o relacionamento das variações graduais das comunidades com as mudanças originadas de alterações ambientais, principalmente as de origens pedológicas e climáticas. Neste caso, cada sítio de estudo particular foi considerado como uma "biogeocenose", um complexo de organismos e variáveis ambientais, e suas inter-relações que, posteriormente, originou o termo "ecossistema" (Odum, 1988).

Diversamente, no método de ordenação, relacionado às escolas inglesa e americana, o objetivo é obter uma representatividade estatística de atributos quantitativos da comunidade, como densidade, frequência e cobertura (dominância) por espécie (Schilling \& Batista, 2008). Conforme estes autores, tais resultados são obtidos por meio da utilização de diversas parcelas distribuídas, aleatória ou sistematicamente, sobre a área de estudo.

Assim, a Fitossociologia foi criada por motivos idiomáticos e científicos, sendo um paralelismo entre a Sociologia Humana e as Ciências Naturais (Porto, 2008). Esta ciência pode ser compreendida como a parte da ecologia quantitativa de comunidades vegetais, envolvendo as inter-relações de espécies vegetais no espaço e, em alguns casos, no tempo, conforme Martins (1991). Seus objetivos referemse ao estudo quantitativo da composição florística, da estrutura, do funcionamento, da dinâmica, da distribuição e das relações ambientais da comunidade vegetal.

Tal como na Europa, no Brasil, a fitossociologia surgiu com aplicação do método de parcelas, utilizando-se as técnicas de análise de BraunBlanquet (Lorenzini, 2006). Os primeiros estudos fitossociológicos no território brasileiro foram realizados por Davis e Veloso, em meados do século XX (Souza, 1989). Porém, somente a partir da década de 1970, estas pesquisas foram sendo gradativamente aplicadas nos ecossistemas brasileiros (Ribeiro, 2004).

O uso de parâmetros sucessionais nas práticas de revegetação passou a ser valorizado e os estudos acerca deste tema se intensificaram (Campelo, 1998; Hosokawa et al., 2008; Kageyama \& Gandara, 2004; Rodrigues et al., 2007). Nos últimos anos, os métodos que se baseavam nestes conhecimentos foram cada vez mais investigados e utilizados nas atividades de recuperação de áreas desenvolvidas por prefeituras e outros órgãos.

Atualmente, informações sobre fitossociologia tornaram-se precípuas para se definirem políticas de conservação, nos programas recuperação de áreas degradadas, na produção de sementes e mudas, na identificação de espécies ameaçadas, na avaliação de impactos e no licenciamento ambiental, dentre outros âmbitos (Brito et al., 2007).

Os inventários florísticos e fitossociológicos prestam-se também para inferir acerca de volume, sortimentos, área basal, altura média das árvores dominantes, biomassa e diâmetro médio 
quadrático. No caso de florestas nativas, outras características também podem ser consideradas, tais como: densidade, dominância, índice de valor de importância, posição sociológica, índice de regeneração natural, etc. Dentre as características qualitativas, podem-se citar vitalidade das árvores, qualidade do fuste, tendência de valorização, etc. (Hosokawa et al., 2008).

Considerando-se a relevância deste tema e os campos de uso destas técnicas, este trabalho visa a atualizar o conhecimento acerca dos métodos que são aplicados no estudo da vegetação, com ênfase no componente arbóreo.

\section{MÉTODOS DE AVALIAÇÃO DA VEGETAÇÃO}

A análise da vegetação pode partir de um censo, ou seja, de uma enumeração completa (100\%) dos indivíduos presentes em uma comunidade florestal (Mantovani et al., 2005). Não obstante, a realização do censo de uma comunidade é raramente praticável, pois requer muito tempo para execução e custo muito elevado (Dias, 2005).

Diversos autores indicam que os ecologistas têm depositado sua confiança nas amostragens feitas para fornecer uma representação segura da composição da comunidade. Um grande esforço tem sido despendido para produzir técnicas de amostragem tão eficientes quanto possível (Dias, 2005; Felfili, 2011).

A escolha do método a ser adotado em um levantamento florestal depende primeiramente do que se pretende responder sobre a vegetação (Durigan, 2003).

Conforme Porto (2008), um estudo detalhado sobre as comunidades deve ser baseado na investigação de seus segmentos. Para esta autora, esses segmentos serão partes representativas da comunidade (amostras ou relevés) e devem considerar o reconhecimento de entidades, baseadas nas homogeneidades das manchas florestais, a seleção de amostras em segmentos reconhecidos e a atenção para as decisões sobre os tamanhos da amostra e da amostragem. Esta autora cita ainda que, para a definição dos critérios de homogeneidade, a escola americana considera os aspectos do estrato herbáceo de uma floresta, enquanto a europeia baseia-se no estrato arbóreo.

Em um estudo fitossociológico, é imprescindível que os pesquisadores satisfaçam alguns requisitos básicos, como: as unidades amostrais devem ser claramente distinguíveis; a forma e o tamanho das unidades devem ser as mais uniformes possíveis; as regras de inclusão e exclusão do material botânico em cada unidade devem ser previamente estabelecidas e respeitadas (Rodrigues, 1989).

Para Medeiros (2004), a amostragem aleatória deve ser a preferida quando não existem variações significativas na comunidade, enquanto a sistemática deve ser utilizada em áreas onde se encontra uma maior variabilidade do componente vegetal.

A técnica de amostragem aleatória deve ser utilizada em comunidades mais homogêneas, enquanto a estratificada deve ser aplicada quanto mais heterogênea for a cobertura vegetal (Souza \& Leite, 1993).

No Brasil, o método de amostragem mais utilizado é o método de parcelas de área fixa, embora seus custos sejam normalmente mais elevados e demandem mais tempo em campo, em função da marcação das unidades amostrais e da numeração de um grande número de indivíduos (Farias et al., 2002).

\subsection{Método do ponto-quadrante}

O Método do Ponto-Quadrante, ou simplesmente Quadrantes, é um método que dispensa a instalação de uma área amostral, oferecendo maior rapidez em sua consecução (Durigan, 2003). A limitação deste método está no número de árvores amostradas em cada ponto, o que torna necessário assumir uma distribuição espacial completamente aleatória, para que se possa ter uma estimativa mais precisa da densidade (Dias, 2005). Portanto, torna-se menos acurada, resultando em superestimativas na densidade quando a população é uniforme ou subestimativas na densidade, para populações agregadas (Martins, 1991).

Este método baseia-se no estabelecimento de inúmeros pontos em uma comunidade florestal, os quais atuam como centro de um plano cartesiano que define quatro quadrantes (Martins, 1991). De 
acordo com este autor, a distância entre os pontos deve ser precisamente determinada, de maneira a evitar que um mesmo indivíduo seja amostrado em dois pontos distintos.

Para alcançar tal precisão, deve-se determinar a distância entre os pontos por meio de uma mensuração prévia de, no mínimo, 50 valores de referência de distância entre dois indivíduos, ao longo de uma comunidade, visando a registrar as maiores distâncias existentes na fitocenose. Posteriormente, é calculada a distância média destas 50 aferições, a qual é elevada ao quadrado para a obtenção de um valor de distância mínima para o estabelecimento dos pontos ao longo do transecto (Vuono, 2002).

Em cada quadrante, é marcado e identificado o indivíduo mais próximo do ponto central que atenda aos critérios de inclusão da amostragem e, em seguida, é registrada a distância deste em relação ao ponto central do quadrante (Durigan, 2003).

O primeiro a relatar o Método dos Quadrantes para estudar uma vegetação tropical foi Goodland, em 1964, na Guiana Inglesa, para uma formação vegetal do tipo savana (Martins, 1991).

O Método dos Quadrantes apresenta inúmeras vantagens, dentre as quais: redução da influência da forma da parcela sobre os resultados; facilidade na locação dos pontos de amostragem; maior área de amostragem; maior consistência na comparação dos resultados obtidos em diferentes povoamentos do mesmo tipo de vegetação; ganho de tempo no campo; maior rapidez e eficiência, e menor necessidade de equipamentos e pessoal (Gorenstein, 2002).

Este método limita-se pelo número de árvores amostradas em cada ponto, o que torna necessário assumir uma distribuição espacial completamente aleatória, para que se possa ter uma estimativa mais precisa da densidade (Dias, 2005). Para este autor, esse padrão nem sempre corresponde à realidade em florestas tropicais naturais, pois estas sempre estão sujeitas a ações, como perturbações antrópicas, diferenças microclimáticas, predação e características do solo, dentre outras.

\subsection{Métodos de área fixa}

No Brasil, a fitossociologia surgiu com a aplicação dos métodos de parcelas, sob forte influência da escola europeia, utilizando-se principalmente as técnicas de análise postuladas por Braun-Blanquet (Lorenzini, 2006).

O método de parcelas consiste no estabelecimento em campo de pequenas unidades amostrais distribuídas pela área de estudo, possibilitando uma representação adequada da diversidade local (Durigan, 2003). As unidades amostrais devem possuir forma e tamanho predefinidos (Durigan \& Leitão-Filho, 1995; Rodrigues, 1989). Todavia, de acordo com Moscovich et al. (1999), a escolha da forma e do tamanho das unidades amostrais vem sendo mais influenciada em função de sua praticidade operacional do que por qualquer outro motivo.

O tamanho das parcelas deve ser coerente com a estrutura da comunidade estudada (Durigan, 2003). Segundo esta autora, no Brasil, utilizam-se normalmente parcelas quadradas de $10 \times 10 \mathrm{~m}$, embora teoricamente as parcelas retangulares sejam consideradas mais representativas. Opostamente, Matteucci \& Colma (1982) recomendam selecionar formas com menor relação perímetro/superfície, para evitar o efeito de borda.

Este método possui as seguintes vantagens: possibilidade de obter todos os estimadores diretamente na unidade amostral e praticidade e simplicidade no estabelecimento das unidades amostrais em campo (Péllico Netto \& Brena, 1997). Estes autores apontam como as principais desvantagens: maior custo na instalação e na manutenção dos limites das unidades amostrais, e número elevado de indivíduos mensuráveis.

Brito et al. (2007) afirmam que este método é mais eficiente quanto à avaliação quantitativa e à avaliação dos parâmetros estimados, bem como para a distribuição espacial dos indivíduos na população.

Este tipo de amostragem pode ser utilizado em estudos de monitoramento e de mudanças de uma mesma comunidade em períodos de tempo mais dilatados, por meio do uso de parcelas permanentes (Martins, 1991). Este recurso, apesar de valioso para avançar no conhecimento da dinâmica da sucessão, ainda tem sido pouco aplicado. 


\subsection{Outros métodos}

O método de Bitterlich (1948 apud Péllico Netto \& Brena, 1996) consiste em contar as árvores em um giro de $360^{\circ}$, cujos diâmetros à altura do peito (DAP) são iguais ou maiores que a abertura angular equivalente a $2 \times \operatorname{sen} \theta / 2$. O vértice do angulo $(\theta)$ é o ponto central da unidade amostral. Dessa forma, a seleção das árvores é feita pela área basal e pela distância. Quanto menor a distância ponto-árvore e maior o seu DAP, maior será a probabilidade do indivíduo ser amostrado. Gorenstein (2002) afirma que este método foi construído para estimar volume e área basal de povoamentos florestais homogêneos, e que também pode ser empregado para estudos ecológicos; porém, sua eficácia estará atrelada à área basal da comunidade, que constitui apenas um dos parâmetros considerados relevantes na amostragem.

Baseando-se no método de Bitterlich, Strand (1958 apud Péllico Netto e Brena, op. cit.) desenvolveu um método para a obtenção dos estimadores de área basal e volume por hectare de uma floresta, utilizando como unidade amostral uma linha com comprimento (L), ao longo da qual se enumeram todas as árvores ou indivíduos situados em seu lado esquerdo e que se qualificam para a amostragem. Para a obtenção dos estimadores de área basal e volume, as árvores incluídas na unidade amostral seguem os preceitos de Bitterlich para a sua inclusão (Moraes \& Silva, 2006). Para a densidade do povoamento, o método foi adaptado por Péllico Netto \& Brena (1996), os quais concluíram que, em florestas adultas o estimador obtido em função do diâmetro apresenta resultados confiáveis.

O método de amostragem conhecido como Prodan, ou das Seis Árvores, teve sua origem na Alemanha (Freiburg), no ano de 1968 (Moscovich et al., 1999). Este método consiste na medição de seis árvores mais próximas de um ponto amostral alocado aleatoriamente em um transecto, sendo o último indivíduo contado como meia árvore, além de suas distâncias até o ponto de referência (sexta árvore) (Pereira Sobrinho, 2003; Faria, 2010). Na medida em que a inclusão de um indivíduo na amostragem depende diretamente da sua distância do ponto amostral, a seleção das árvores é determinada pelas mudanças na probabilidade de encontrar árvores de acordo com a distância de cada ponto (Faria, 2010).

Os métodos supracitados apresentam vantagens por serem de fácil operacionalização em campo e proporcionarem poucos erros de demarcação, estabelecendo uma rede de pontos amostrais bem distribuídos dentro da comunidade e permitindo, assim, uma visão mais abrangente da fitocenose. Todavia, possuem pouca aplicação no Brasil, restringindo-se a estudos acadêmicos, com objetivo de comparar a eficácia entre metodologias de amostragem em estudos florestais (Péllico Netto \& Brena, 1996; Gorenstein, 2002; Padoin, 2007; Brito et al., 2007; Faria, 2010).

\section{SUFICIÊNCIA AMOSTRAL}

A suficiência amostral é um conceito quantitativo para informar se a amostra utilizada é representativa da comunidade vegetal em estudo (Mueller-Dombois \& Ellenberg, 1974).

A área mínima necessária ao estudo da vegetação deve ser determinada, em primeira instância, por meio da análise da homogeneidade e do status de fragmentação da cobertura vegetal (Porto, 2008).

A literatura aponta algumas técnicas para avaliar o grau de efetividade da amostragem em um levantamento florestal. Dentre estas, podem-se citar: curva de acumulação de espécies (ou curva espécies área, ou curva do coletor), métodos apoiados em regressão linear de platô ou, até mesmo, algoritmos matriciais.

A 'curva de acumulação de espécies' é uma representação gráfica com grande utilização nas áreas de ecologia, fitossociologia e inventário florestal (Schilling \& Batista, 2006). A análise consta de figuras relacionando o esforço amostral (número de indivíduos amostrados ou área amostral) cumulativo (eixo $\mathrm{X}$ ) com o número cumulativo de espécies amostradas (eixo Y) (Martins \& Santos, 1999).

Kylin (1926 apud Braun-Blanquet, 1979) desenvolveu um modelo logarítmico denominado de curva espécie-área e recomendou seu uso para determinar a menor superfície necessária para incluir a combinação característica das espécies que definem a associação. Em seu pressuposto, inicialmente o número de espécies aumenta rapidamente; em 
seguida, os ingressos vão sendo menores, até que, por fim, a curva tenda à estabilização, assumindo uma forma assintótica, ou seja, quase paralela ao eixo X.

Os estudos realizados por Pielou (1977) originaram a curva baseada tanto em número de indivíduos quanto em área, denominada de curva do coletor. Este modelo tem sido geralmente utilizado para verificar o que muitos chamam de área mínima de amostragem.

Conforme Martins \& Santos (1999), um número significativo de pesquisadores adota a curva do coletor para verificar o que muitos chamam de área mínima e outros chamam de suficiência amostral. Segundo estes autores:

[...] esta é uma interpretação incorreta da função da curva. Por outro lado, chamar a curva do coletor baseada em área de curva espécie-área é também totalmente errôneo, pois as relações espécie-área prevêem a existência de áreas de tamanhos diferentes, independentes entre si, o que não é o mesmo caso de unidades amostrais sendo somadas. Cada vez que se somam as unidades amostrais para expressar o tamanho cumulativo da amostra, a soma inclui todas as unidades amostrais anteriores, de forma que cada área acumulada é totalmente dependente da área acumulada anteriormente. (Martins \& Santos, 1999, p. 257).

Batista \& Schilling (2006) afirmam que a curva do coletor apresenta uma séria limitação, pois a arbitrariedade da ordem de entrada das unidades amostrais na construção da curva nem sempre reflete verdadeiramente a distribuição dos indivíduos em uma comunidade.

Mesmo diante destes aspectos, tradicionalmente o procedimento mais usado para definir a suficiência amostral vem da interpretação extraída por meio da curva do coletor, pela "inspeção visual" da curva, para identificar o ponto em que se inicia o patamar de estabilização. Com esta técnica, verifica-se que o ponto em que a curva atinge o seu ponto de assíntota - ou seja, uma linha reta que se aproxima indefinidamente da curva sem interceptá-la - pode ser interpretado como o ponto no qual grande parte da diversidade da composição local foi inventariada (Mueller-Dombois \& Ellenberg, 1974; Brower \& Zar, 1984; Pinto-Coelho, 2000; Cullen Junior et al., 2004).

Cain (1938 apud Schilling \& Talora, 2004) argumenta que a visualização do patamar é fundamentalmente um artifício gráfico, pois, dependendo da relação entre o comprimento dos eixos x e y (abscissas e ordenadas), o patamar pode ou não ser visualizado. Por exemplo, uma abscissa longa, grafada contra uma ordenada curta, sempre reforçará a visualização de um 'patamar'. Como forma de mitigar esta distorção, Cain (1938 apud Lamprecht, 1990) recomenda que seja considerada como área mínima não aquela em que a curva se torne horizontal, mas sim aquela em que um aumento de $10 \%$ da área amostrada represente no máximo um aumento de $10 \%$ do número total de espécies novas ou, de uma forma mais rígida, que a $10 \%$ do aumento da área total represente um aumento de até 5\% do total de espécies.

Para mitigar estas inconsistências metodológicas, é comum o uso das técnicas de bootstrap e jackknife, ou seja, um procedimento de aleatorização em que são realizadas sucessivas reamostragens com reposição na própria amostra obtida, com o objetivo de avaliar o grau de estabilidade dessa amostra, permitindo, assim, a determinação da suficiência amostral a partir de curvas de acumulação de espécies (Krebs, 1989).

Durigan (2009) recomenda que, ao se utilizar a curva de acumulação de espécies, é coerente adotar como variável independente o número de indivíduos em vez do número de espécies e construí-la mediante a rarefação. Para Martins \& Santos (1999), a partir desta técnica é possível gerar a estimativa de uma curva média, baseada em $\mathrm{n}$ simulações com os dados coletados, permitindo também a obtenção de medidas de variação (desvio padrão e variância), de modo que a figura incorpore o intervalo de confiança da curva.

\section{FISIONOMIA E FLORÍSTICA}

A Sinfisionomia é uma parte da Botânica que estuda as comunidades vegetais sem a necessidade de identificar as espécies vegetais presentes na área de estudo (Lousã et al., 2007; Ariza, 2010).

Conforme Longhi (1991), a fisionomia é o estudo da 'aparência' da vegetação e, para analisá-la, devem ser consideradas as características morfológicas das plantas constituintes, bem como a estrutura da comunidade vegetal. Para Fernandes (2000), prende-se à configuração da cobertura vegetal em 
sua expressão estereognóstica (capaz de perceber e reconhecer a sua forma pela textura, pelo tamanho, pelas propriedades espaciais), sendo identificável pela sua aparência e visualizada pela natureza do agrupamento fitológico.

A Fisionomia manifesta-se pelas formas de vida dos componentes florísticos, identificadas pelo desenvolvimento vegetativo (árvore, arbusto, ervas, cipós, etc) e também pelo desenvolvimento fenológico, observado pelo comportamento foliar (pereneidade ou estacionalidade) (Fernandes, 2000).

Segundo Montoya-Maquin (1966), para se estudar a fisionomia da vegetação, devem-se analisar certas características da mesma, como as funções (características morfológico-biológicas) das espécies que formam a estrutura ou a distribuição espacial destas na comunidade.

Por outro lado, a composição florística visa a indicar o conjunto de unidades taxonômicas que compõem a floresta, como as suas espécies e famílias (Schneider \& Finger, 2000). O objetivo de um levantamento florístico é listar as espécies vegetais ocorrentes em determinada área (Cavassan et al., 1984).

A Florística também é empregada muito comumente no campo da Fitogeografia (sensu strictu), associando a distribuição das plantas na superfície terrestre com as causas relacionadas à formação de tais padrões, como: movimentos continentais, alterações climáticas, modificações pedológicas e migrações e mudanças faunísticas, dentre outras (Fernandes, 2003).

Hosokawa et al. (2008) salientam que os estudos florísticos, além de gerar informações sobre classificação e distribuição taxonômica no nível de família e espécie de uma comunidade vegetal, também podem subsidiar informações sobre atributos ecológicos das espécies, como formações de grupos ecológicos, síndromes de dispersão, fenologia e formas de vida, dentre outros.

Os estudos florísticos representam uma importante etapa no conhecimento de um ecossistema por fornecer informações básicas para os estudos biológicos subsequentes (Guedes-Bruni et al., 1997). Tais informações podem ser utilizadas na elaboração e no planejamento de ações que objetivem a conservação, o manejo e/ou mesmo a recuperação das formações florestais, procurando, ao máximo, retratar as suas diversidades (Durigan, 2003; Borém \& Ramos, 2001)

\section{RIQUEZA E DIVERSIDADE}

A biodiversidade refere-se ao estudo das relações quantitativas entre a riqueza de diferentes categorias biológicas e a abundância relativa de espécies dentro das comunidades, incluindo variabilidade no nível local (diversidade alfa), complementaridade biológica entre habitats (diversidade beta) e variabilidade entre paisagens (diversidade gama) (Santos, 2009).

Em uma primeira instância, a diversidade poderia ser mensurada de forma direta, utilizandose a riqueza de espécies, ou seja, o número de espécies existentes em uma área de interesse. Porém, torna-se praticamente impossível contar todas as espécies numa determinada comunidade, haja vista a presença de espécimes de um grande número de espécies (especialmente nas regiões tropicais), as elevadas taxas de migrantes e o elevado número de espécies coletadas apenas uma ou duas vezes em cada área de estudo (Melo, 2008).

A segunda forma de padronizar a diversidade seria considerando, por intermédio da interpolação (rarefação) ou da extrapolação, a riqueza de espécies por meio de diferentes índices de riqueza (Melo, 2008).

Quando empregados em áreas delimitadas, no espaço e no tempo, os índices de riqueza apresentam estimativas muito úteis, expressando de forma compreensível e instantânea a diversidade. Entre estes índices, podem-se citar o de Gleason, o de Margalef e o de Menhinick. Nestes três casos, é suposta uma relação linear entre a riqueza de espécies e o número de indivíduos (Matos et al., 1999).

$\mathrm{O}$ índice de Gleason $\left(\mathrm{D}_{\mathrm{g}}\right)$ é um índice simples de diversidade, que considera somente o número de espécies (s) e o logaritmo (base 10 ou natural) do número total de indivíduos (Rodrigues, 2007) (Quadro 1). Da mesma forma, o índice de Margalef também é um índice simples de diversidade, que considera o número de espécies (s-1) e o logaritmo (base 10 ou natural) do número total de indivíduos (Gurevitch et al., 2009). A diversidade de Menhinick 
Quadro 1. Índices de diversidade aplicados aos estudos de ecologia vegetal, incluindo suas fórmulas e descritores. Chart 1. Diversity indices applied to studies of plant ecology, including formulas and their descriptors.

\begin{tabular}{|cll|}
\hline Índices & Fórmulas & \multicolumn{1}{c|}{ Descritores } \\
\hline Gleason & $D_{g}=\frac{s}{\log N}$ & $\begin{array}{l}\mathrm{s} \text { - número de espécies amostradas; } \\
\mathrm{N} \text { - número total de indivíduos em todas as espécies. }\end{array}$ \\
\hline Margalef & $\alpha=\frac{s-1}{\log \mathrm{N}}$ & $\begin{array}{l}\mathrm{s} \text { - número de espécies amostradas; } \\
\mathrm{N}-\text { número total de indivíduos em todas as espécies. }\end{array}$ \\
\hline Menhinick & $D_{b}=\frac{s}{\sqrt{N}}$ & $\mathrm{~s}$ - número de espécies amostradas; \\
\end{tabular}

Fonte: Rodrigues (2007); Gurevitch (2009).

$\left(\mathrm{D}_{\mathrm{b}}\right)$ é um índice simples de diversidade que considera o número de espécies (s) e a raiz quadrada do número total de indivíduos (Gurevitch et al. Op. Cit.).

Uma vantagem na aplicação destes índices é que, para uma mesma comunidade, eles tendem a assumir um valor constante em relação a aumentos no esforço amostral (Melo, 2008).

Por outro lado, os índices supracitados podem apresentar uma forte inconsistência ecológica, já que cada comunidade apresenta suas próprias características, como, por exemplo, quanto à distribuição de indivíduos entre espécies (Matos et al., 1999).

Assim, a terceira forma pela qual se pode medir diversidade é o uso de índices de diversidade, os quais combinam dois atributos de uma comunidade: riqueza de espécies e equabilidade (ou equitabilidade) (Martins \& Santos, 1999).

Melo (2008) utilizou duas situações para demonstrar o componente 'equabilidade' considerado pelos índices de diversidade. Para tanto, são utilizados, como exemplo, duas florestas com cem árvores distribuídas em dez espécies: I - na primeira floresta, cada espécie é representada por dez indivíduos; II - na segunda floresta, uma das espécies teria 91 indivíduos e as espécies restantes teriam cada uma apenas um indivíduo. Embora a riqueza de espécies seja a mesma (10), no segundo caso fica evidente a 'sensação' de menor diversidade ou de maior monotonia, já que ocorre o predomínio de uma espécie em detrimento das demais.

A maioria dos índices de diversidade é não paramétrica, pois estes independem de parâmetros de uma distribuição, como, por exemplo, a distribuição normal. Tais índices, geralmente, consistem de expressão matemática simples envolvendo a abundância relativa de cada espécie na amostra (Melo, 2008). Conforme Oliveira (1997), os estimadores não paramétricos podem ser muito úteis para prever o número de espécies de uma área, tendo a vantagem da simplicidade nos cálculos, visto que são necessárias apenas as informações quanto ao número de espécies que se apresentam em uma ou duas parcelas utilizadas na amostragem.

O índice de Simpson foi o primeiro a ser usado em estudos ecológicos e mostra a 'concentração' de dominância, uma vez que quanto maior o valor, maior a dominância por uma ou poucas espécies (Matos et al., 1999). Segundo Pinto-Coelho (2000), Simpson, ao postular sua teoria, baseou-se na seguinte pergunta: Qual a probabilidade de que dois indivíduos tomados ao acaso tomadas ao acaso em uma comunidade de tamanho infinito pertençam à mesma espécie? Assim, o índice de dominância de Simpson mede a probabilidade de dois indivíduos, selecionados ao acaso na amostra, pertencerem à mesma espécie. Este índice possui uma vantagem em relação aos índices de Margalef, Gleason e Menhinick, pois não somente considera o número de espécies (s) e o total de números de indivíduos $(\mathrm{N})$, mas também a proporção do total de ocorrência de cada espécie (Rodrigues, 2007).

De acordo com Brower \& Zar (1984), os índices de diversidade mais aplicados nos estudos ecológicos são os de Shannon (H') e Pielou (J).

O índice de Shannon, derivado da Teoria da Informação, adota unidades que variam conforme a base logarítmica usada - bits (base 2), nats (base 
neperiana) ou decits (base 10) - e considera a riqueza das espécies e suas abundâncias relativas (Odum, 1988; Melo, 2008). Sua concepção admite que os indivíduos sejam coletados aleatoriamente de uma grande e infinita população, assumindo, também, que todas as espécies estão representadas na amostra (Dias, 2004).

Outro grupo de índices de diversidade são aqueles em que, além da riqueza de espécies e da equabilidade, incorporam-se as distâncias ou diferenças (morfológica, funcional, filogenética) entre as espécies. Estes índices podem ser particularmente úteis em estudos de conservação, nos quais se procura maximizar não apenas riqueza de espécies, mas também o número de clados ou grupos taxonômicos (Melo, 2008).

Uma vantagem, embora discutível, do uso dos índices de diversidade seria concentrar numa mesma medida dois atributos da comunidade, já que ambos são capazes de proporcionar a 'sensação' de diversidade (Melo, 2008).

De acordo com Odum (1988), o índice de Shannon atribui um peso maior às espécies raras, enquanto o índice de Pielou representa a proporção da diversidade de espécies encontradas na amostragem atual em relação à diversidade máxima que a comunidade poderá atingir. $\mathrm{O}$ índice de Simpson apresenta vantagem em relação ao índice de Shannon, pois não exige conhecimento sobre todas as espécies de uma sinúsia na comunidade; porém, tem a desvantagem de ser pouco utilizado e, desta forma, menos comparável em relação ao índice de Shannon.

Segundo Daniel (1998), o índice de Shannon apresenta diversas vantagens: é capaz de medir os níveis de diversidade em diferentes ecossistemas e para objetos diferentes; contém propriedades que permitem os testes estatísticos, tais como a comparação de valores em momentos diferentes, na mesma população ou comunidade, e baseia-se em dois parâmetros importantes nas comunidades, que são o número de espécies e a abundância, dentre outros.

Por outro lado, o emprego de índices de diversidade muitas vezes é restrito a situações comparativas (Melo, 2008). Como saber, por meio do índice de Shannon, que a comunidade A é mais diversa do que a comunidade B? Este índice sempre estará na dependência de uma base comparativa, o que necessita de procedimentos metodológicos semelhantes (critério de inclusão, tamanho e forma de unidades amostrais, semelhanças fitogeográficas e rigor na identificação taxonômica, dentre outros). Um segundo problema no uso destes índices é que o valor obtido para uma comunidade não permite saber exatamente a natureza da comunidade. Infinitas combinações de riqueza de espécies e equabilidade poderiam gerar exatamente o mesmo valor. Como consequência, pode-se obter o mesmo valor de índice de diversidade para duas comunidades diferentes em riqueza de espécies e equabilidade (Melo, 2008).

Dias afirma que,

[...] uma das grandes críticas que se tem feito a esse índice é justamente o fato de que o cálculo da diversidade baseado na abundância relativa não dá nenhuma resposta ecológica plausível de análise depois de computada. Por ser muito robusto, esse índice pode ser usado em comparações através das variâncias [medida de tendência central que informa a variação em torno da média] obtidas durante o cálculo do valor do índice (H') por testes t de Student. (Dias, 2004, p. 375).

As diferentes formas de efetuar os cálculos de índices de diversidade para o mesmo conjunto de dados podem, muitas vezes, causar equívocos em suas interpretações. Dias (2004) aponta que existe uma forma de quantificar se ocorre diferença da diversidade, que é por meio dos modelos baseados na distribuição da abundância relativa das espécies, conforme o Quadro 2:

Recentemente, o uso dos estimadores de riqueza de espécies vem sendo apontado como uma alternativa para um conjunto de dados com diferentes distribuições de abundância, ajustando o peso das espécies raras, ou seja, aquelas que só aparecem em uma ou em poucas amostras (Dias, 2004). Os principais estimadores e seus pressupostos estão resumidos no Quadro 3.

A escolha de um determinado índice depende invariavelmente dos objetivos e escalas espaciais do estudo. Em estudos de Macroecologia, envolvendo escalas continentais, apenas dados de presença/ausência estão disponíveis, impossibilitando o uso de índices de riqueza, índices 
Quadro 2. Modelos de distribuição de abundância aplicados aos estudos de ecologia vegetal, incluindo seus descritores.

Chart 2. Models of abundance distribution applied to studies of plant ecology, including its descriptors.

\begin{tabular}{|cl|}
\hline Modelos & \multicolumn{1}{c|}{ Pressupostos } \\
\hline Log normal & $\begin{array}{l}\text { Usado quando a abundância das espécies e as classes de abundância devem ser } \\
\text { expressas em logaritmos na base 2 e esse resultado de padrão de distribuição é } \\
\text { chamado de oitavas. }\end{array}$ \\
\hline Log série & $\begin{array}{l}\text { Usado para descrever matematicamente a relação entre o número de espécies e } \\
\text { seu número de indivíduos originalmente em pesquisas entomológicas (em que as } \\
\text { populações são, em sua maioria, hiperabundantes). }\end{array}$ \\
\hline Série geométrica & $\begin{array}{l}\text { Usado em modelos em que o padrão de abundância é encontrado primariamente em } \\
\text { ambientes com uma comunidade simples e relativamente pequena ou em ambientes } \\
\text { com estágios de sucessão recentes. }\end{array}$ \\
\hline 'Vara quebrada' ou Broken Stick & $\begin{array}{l}\text { Usado para ordenar o número de indivíduos das espécies mais abundantes de uma } \\
\text { comunidade; utilizado como proposta para cálculo de sobreposição de nicho. }\end{array}$ \\
\hline
\end{tabular}

Fonte: Dias (2004).

Quadro 3. Modelos de estimadores de riqueza aplicados aos estudos de ecologia vegetal, incluindo suas fórmulas e descritores.

Chart 3. Models of richness estimators applied to studies of plant ecology, including formulas and their descriptors.

\begin{tabular}{|cl|}
\hline Estimadores & \multicolumn{1}{c|}{ Pressupostos } \\
& $\begin{array}{l}\text { Estimador de riqueza baseado na extrapolação [adição aleatória da ordem das amostras] das } \\
\text { curvas de acúmulo de espécies. A proposta dessas curvas é que elas representam o número } \\
\text { de espécies descobertas, plotadas em um gráfico que indique qual foi a quantidade de esforço } \\
\text { empregado para se inventariar uma área, por exemplo. Pela observação do comportamento da } \\
\text { curva, pode-se fazer uma previsão de quantas espécies (que não foram coletadas) ainda podem } \\
\text { vir a ser descobertas. }\end{array}$ \\
\hline Jackknife 1 e 2 & $\begin{array}{l}\text { Estimador de riqueza baseado na abundância (abundância aqui quantifica raridade ou o número } \\
\text { de singletons/doubletons - o número de espécies representadas por somente 1 ou 2 indivíduos, } \\
\text { respectivamente). }\end{array}$ \\
\hline Chao 1 e 2 & $\begin{array}{l}\text { Chao 1 - estimador de riqueza baseado na abundância; Chao 2 - estimador de riqueza baseado } \\
\text { na incidência de espécies (ou presença/ausência dos dados que quantifiquem raridade ou o } \\
\text { número de uniques/duplicates - o número de espécies encontradas em somente 1 ou 2 amostras, } \\
\text { respectivamente). }\end{array}$ \\
\hline Bootstrap & $\begin{array}{l}\text { Estimador de riqueza baseado na incidência de espécies; esta ferramenta estandardiza as } \\
\text { comparações de riqueza de espécies a um número em comum de indivíduos. }\end{array}$ \\
\hline ACE & $\begin{array}{l}\text { Estimador baseado no conceito de cobertura de amostra (abundância ou o número de singletons/ } \\
\text { doubletons). }\end{array}$ \\
\hline ICE & $\begin{array}{l}\text { Estimador baseado no conceito de cobertura de amostra (ou presença/ausência dos dados que } \\
\text { quantifiquem raridade - ou o número de uniques/duplicates). }\end{array}$ \\
\hline
\end{tabular}

Fonte: Dias (2004); Gotelli (2009).

de diversidade paramétricos ou não paramétricos, ou ainda riquezas interpoladas ou extrapoladas. Nestes estudos, geralmente o interesse é focado em revelar padrões e processos, ecológicos e evolutivos, geradores de riqueza de espécies numa região. Geralmente, não existe interesse em saber a importância relativa de cada espécie em cada região. O mesmo é válido para estudos de Conservação que tenham como objetivo produzir métodos que maximizem o número de espécies a serem protegidas (Melo, 2008).

Não existe uma solução própria para as questões de biodiversidade, na medida em que as soluções permeiam por diferentes alternativas, que devem ser escolhidas com discernimento, responsabilidade e sensibilidade (Matos et al., 1999). 


\section{PARÂMETROS DA ESTRUTURA HORIZONTAL}

A Fitossociologia, como ciência, busca conhecer a comunidade vegetal do ponto de vista florístico e estrutural (Braun-Blanquet, 1979).

Um estudo fitossociológico não se apoia somente no conhecimento das espécies que compõem a flora, mas, acima de tudo, em como elas estão arranjadas, sua interdependência, como funcionam e como se comportam no fenômeno de sucessão (Rodrigues \& Pires 1988).

Segundo Mueller-Dombois \& Ellenberg (1974), Braun-Blanquet (1979), Lamprecht (1990) e Martins (1991), a caracterização fitossociológica das florestas pode ser feita mediante cálculos de abundância (densidade), frequência e dominância.

A frequência é um descritor do número de observações realizadas pelo pesquisador de seu objeto de estudo e é expressa normalmente em forma de porcentagem. Esse parâmetro pode ser absoluto, quando calculado em função de uma área amostral ou outra subdivisão criada pelo pesquisador, ou relativo, obtido pela proporção entre a frequência absoluta de determinada espécie e a soma das frequências absolutas das demais espécies inventariadas (Mueller-Dombois \& Ellenberg, 1974; Braun-Blanquet, 1979; Brower \& Zar, 1984; Martins, 1991; Pinto-Coelho, 2000; Cullen Junior et al., 2004).

A densidade é um parâmetro ecológico que revela a ocupação do espaço pelo indivíduo e, assim como a frequência, podem ser calculadas tanto as densidades absolutas quanto as relativas. Este parâmetro, a desidade absoluta, representa o número total de indivíduos de uma determinada espécie em uma área/volume total amostrada, enquanto que a densidade relativa é a relação entre a abundância total de uma determinada espécie na amostra e a abundância total da amostra (Mueller-Dombois \& Ellenberg, 1974; Braun-Blanquet, 1979; Brower \& Zar, 1984; Martins, 1991; Pinto-Coelho, 2000; Cullen Junior et al., 2004).

A estrutura horizontal de uma floresta, sucintamente, resulta das características e combinações entre as quantidades em que cada espécie ocorre por unidade de área (densidade), da maneira como estas espécies se distribuem na área (frequência) e do espaço que cada uma ocupa no terreno (dominância) (Barros, 1980; Lamprecht, 1990).

Ao se transformarem os valores absolutos em valores relativos, é possível obter o Valor de Cobertura (VC) e o Valor de Importância (VI), preteritamente conhecidos como Índice de Valor de Cobertura (IVC) e Índice de Valor de Importância (IVI), respectivamente (Martins, 1991). O primeiro é obtido por meio da soma de densidade e dominância relativas. Este permite estabelecer a estrutura dos táxons na comunidade e separar diferentes tipos de uma mesma formação, assim como relacionar a distribuição das espécies em função de gradientes abióticos.

O Valor de Importância, proposto por Curtis e Macintosh (1950 apud Moscovich, 2006), é obtido somando-se, para cada espécie, os valores relativos de Densidade, Dominância e Frequência, obtendo-se um valor máximo de 300\%. O Valor de Importância pode ser convertido em Porcentagem de Importância, ao ser dividido por três. Este é a combinação dos valores fitossociológicos relativos de cada espécie, com finalidade de atribuir um valor para as espécies dentro da comunidade vegetal a que pertencem (Matteucci \& Colma, 1982).

A soma de diferentes descritores, se por um lado pode distorcer as relações entre as variáveis estudadas, por outro, permite visualizar de forma ampla o desempenho das espécies na comunidade (Martins, 1991).

Daubenmire (1968 apud Moscovich, 2006) observa que, ao serem somados os três parâmetros, o valor de Frequência tende a mascarar os demais, apresentando, portanto, um maior peso na definição do Valor de Importância. Por isto, Cain et al. (1956 apud Moscovich, 2006) chamam a atenção para o fato de os valores de Frequência serem afetados pelas características das parcelas e da amostragem.

Martins (1991) afirma que, apesar de críticas, o Valor de Importância tem se revelado muito útil tanto para separar tipos diferentes de florestas como para relacioná-las a fatores ambientais, incluindo as relações entre a distribuição de espécies e os fatores abióticos.

Os descritores ou parâmetros da Estrutura Horizontal de uma comunidade florestal são 
calculados conforme as fórmulas descritas abaixo (Quadro 4).

Conforme Sampaio et al. (1993), nenhum parâmetro fitossociológico isolado fornece uma ideia ecológica clara da comunidade ou das populações vegetais. Em conjunto, podem caracterizar formações (e suas subdivisões) e suprir informações sobre estágios de desenvolvimento da comunidade e das populações, distribuição de recursos ambientais entre populações, possibilidades de utilização dos recursos vegetais, etc.

As combinações mais importantes, sob os aspectos ecológico, estrutural e silvicultural, para os parâmetros densidade, frequência e dominância, podem ser consideradas em seis condições, conforme descritos por Lamprecht (1990):

- Elevados valores de Densidade, Frequência e Dominância: representam as espécies mais importantes, quando analisada apenas a estrutura da comunidade;
- Densidade e Frequência elevadas: condição típica para as espécies de ocorrência horizontal regular;

- Densidade elevada e baixa Frequência: fenômeno típico para espécies com certa aglomeração local;

- Densidade e Dominância elevadas e baixa Frequência: indica espécies de grande porte;

- Densidade elevada e baixos valores de Frequência e Dominância: indica a presença de espécies de povoamento auxiliar com tendência ao agrupamento;

- Baixa Densidade e elevados valores de Frequência e Dominância: condição típica para árvores dominantes isoladas e em número reduzido, porém dispersas com certa regularidade por áreas relativamente grandes.

Atualmente, em estudos ecológicos, é comum a aplicação de análises multivariadas, ou seja, análises que correspondem a um grande número de métodos e técnicas que utilizam, simultaneamente, todas as variáveis na interpretação teórica do conjunto de dados obtidos (Gauch Junior, 1982). O conhecimento das técnicas multivariadas e das

Quadro 4. Descritores fitossociológicos aplicados ao estudo da estrutura horizontal de comunidades vegetais. Chart 4. Phytosociological descriptors applied to the study of the horizontal structure of plant communities.

\begin{tabular}{|c|c|}
\hline $\begin{array}{l}\text { Frequências Absoluta e Relativa } \\
F A_{i}=\left(\frac{u_{i}}{u_{t}}\right) \times 100 \\
F R_{i}=\left(\frac{F A_{i}}{\sum_{i=1}^{P} F A_{i}}\right) \times 100\end{array}$ & $\begin{array}{l}\mathrm{FA}_{\mathrm{i}}=\text { frequência absoluta da i-ésima espécie na comunidade vegetal; } \\
\mathrm{FR}_{\mathrm{i}}=\text { frequência relativa da i-ésima espécie na comunidade vegetal; } \\
\mathrm{u}_{\mathrm{i}}=\text { número de unidades amostrais em que a i-ésima espécie ocorre; } \\
\mathrm{u}_{\mathrm{t}}=\text { número total de unidades amostrais; } \\
\mathrm{P}=\text { número de espécies amostradas. }\end{array}$ \\
\hline $\begin{array}{l}\text { Densidades Absoluta e Relativa } \\
\qquad A_{i}=\frac{n_{i}}{A} \\
D R_{i}=\frac{D A_{i}}{D T} \times 100\end{array}$ & $\begin{array}{l}\mathrm{DA}_{\mathrm{i}}=\text { densidade absoluta da i-ésima espécie, em número de indivíduos } \\
\text { por hectare; } \\
\mathrm{n}_{\mathrm{i}}=\text { número de indivíduos da i-ésima espécie na amostragem; } \\
\mathrm{n}_{\mathrm{i}}=\text { número total de indivíduos amostrados; } \\
\mathrm{A}=\text { área total amostrada, em hectare; } \\
\mathrm{DR}_{\mathrm{i}}=\text { densidade relativa }(\%) \text { da i-ésima espécie. }\end{array}$ \\
\hline $\begin{array}{l}\text { Dominâncias Absoluta e Relativa } \\
\qquad o A_{i}=\frac{A B_{i}}{A} \\
D o R_{i}=\frac{D o A}{D o T} \times 100\end{array}$ & $\begin{array}{l}\mathrm{DoA}_{\mathrm{i}}=\text { dominância absoluta da i-ésima espécie, em } \mathrm{m}^{2} / \mathrm{ha} ; \\
\mathrm{AB}_{\mathrm{i}}=\text { área basal da i-ésima espécie, em } \mathrm{m}^{2} \text {, na área amostrada; } \\
\mathrm{A}=\text { área amostrada, em hectare; } \\
\mathrm{DoR}_{\mathrm{i}}=\text { dominância relativa (\%) da i-ésima espécie. }\end{array}$ \\
\hline $\begin{array}{l}\text { Valor de Importância } \\
V I_{i}=D R_{i}+D o R_{i}+F R_{i} ; V I_{i}(\%)=\frac{V I_{i}}{3}\end{array}$ & \\
\hline $\begin{array}{l}\text { Valor de Cobertura } \\
V C_{i}=D R_{i}+D o R_{i} ; V C_{i}(\%)=\frac{V C_{i}}{2}\end{array}$ & \\
\hline
\end{tabular}

Fonte: Mueller-Dombois \& Ellenberg (1974). 
suas possibilidades de aplicação em estudos de vegetação fornece ao pesquisador a oportunidade de explorar e interpretar, de forma objetiva, os resultados dos seus estudos e, a partir deles, testar ou formular hipóteses de trabalho (Gotelli \& Ellison, 2011). Quando o objetivo do estudo é descrever a vegetação, os métodos de classificação (como Cluster e Twinspan) são mais adequados (Oliveira-Filho, 1989; Narvaes, 2008), enquanto que os métodos de ordenação (PCA - Análise de Componentes Principais, CA - Análise de Correspondência e outras) são mais indicados quando o objetivo é determinar relações entre a vegetação e o ambiente, mesmo que indiretamente (Santos et al., 2004). Quando se trabalha com um conjunto de dados muito heterogêneos, geralmente é necessário primeiro classificar e, em seguida, ordenar cada grupo separadamente (Machado et al., 2004).

\section{PARÂMETROS DA ESTRUTURA VERTICAL}

Para Longhi et al. (1992), as comunidades variam de acordo com o número de estratos que apresentam, dependendo da variedade de formas de vida que estão presentes na comunidade, refletindo as condições pedológicas, climáticas e as ações dos fatores bióticos que interagem no ambiente.

A estrutura vertical (ou posição sociológica) é aquela que define o arranjo de diferentes sinúsias, ou dos diferentes estratos com suas espécies características, que integram uma comunidade vegetal. Segundo Herrera et al. (2009), é comum notar uma diferenciação vertical ou estratificação determinada, principalmente, pela resposta à redução da taxa de luminosidade pelo perfil vertical das florestas.

As informações referentes aos estudos da estrutura vertical, aliadas às estimativas dos parâmetros fitossociológicos da estrutura horizontal, propiciam uma caracterização mais completa da importância ecológica das espécies na comunidade florestal (Senra, 2000).

\section{Conforme Pereira-Silva,}

[...] através das análises fitossociológicas horizontal e vertical, a estrutura da comunidade vegetal pode ser representada como um todo e comparada com outras comunidades tanto do ponto de vista da composição de espécies como da abundância de suas populações por estrato. (Pereira-Silva et al., 2004, p. 534).

De acordo com Hack,

[...] a presença de espécies nos diferentes estratos é de fundamental importância fitossociológica, pois uma espécie tem presença assegurada na estrutura e dinâmica da floresta, quando se encontra representada em todos seus estratos. (Hack et al., 2005, p. 1084).

De acordo com Guapyassú,

[...] o reconhecimento dos estágios serais (seres) é de vital importância para os estudos de composição florística, fisionomia e estrutura, pois estas diferem de acordo com o estágio sucessional em que a comunidade se encontra. (Guapyassú, 1994, p. 14).

Essa autora ressalta ainda que, em florestas tropicais "[...] observa-se a conveniência de denominar estas seres de pioneira, secundária inicial, secundária tardia e clímax." (Guapyassú, 1994, p. 14). A análise da estrutura vertical infere sobre o estágio seral em que a espécie se encontra dentro de uma comunidade florestal. A partir desta análise, é possível constatar a importância da espécie, em cada estrato (Hosokawa et al., 2008).

A literatura especializada apresenta uma série de metodologias para identificar e reconhecer a presença de estratos em florestas. Sanquetta (1995) cita as contribuições de Monsi e Saeki (1953), Ogawa et al. (1963) e Richards (1979), porém afirma que estas são trabalhosas, parciais, aplicáveis em pequenas áreas e, muitas vezes, destrutivas.

Sanquetta (1995) apresentou um método de estratificação florestal adaptado de Hozumi (1975), denominado de diagrama $h$-M. Este consiste em plotar a distribuição dos dados referentes à variável altura $(h)$ em oposição aos valores das variáveis $h$, que representam os melhores resultados da própria altura, distribuídos no eixo das ordenadas.

Também foi muito utilizada a classificação da IUFRO, proposta por Leibundgut (1958 apud Lamprecht, 1990), que parte da altura dominante $\left(\mathrm{H}_{\text {dom }}\right)$ da floresta para distinguir os estratos, conforme apresentado nas equações 1, 2 e 3 :

inferior $\left(h<\frac{h_{\text {dom }}}{3}\right)$ 
médio $\left(\frac{h_{d o m}}{3} \leq h<\frac{2 h_{d o m}}{3}\right)$

superior $\left(h \geq \frac{2 h_{d o m}}{3}\right)$

Longhi (1980 apud Moscovich, 2006) publicou um método constituído por meio de uma curva de frequências acumuladas, baseado na frequência relativa das alturas e fixado em três estratos, abrangendo em cada estrato um terço das alturas.

Outro método, citado por Souza et al. (2003), divide a floresta em três estratos de altura total, sendo: estrato inferior - compreende as árvores com altura total $(H)$ menor que a altura média $(\mathrm{Hm})$ menos uma unidade de desvio padrão (1 s) das alturas totais, ou seja, $H<(H m-1 \mathrm{~s})$; estrato médio - compreende as árvores com $(H m-1 \mathrm{~s})$ $\leq H<(H m+1 \mathrm{~s})$; estrato superior - compreende as árvores com $H \geq(H m+1 \mathrm{~s})$. Souza et al. (2003) recomendam a aplicação de análises multivariadas para a determinação da estratificação florestal, a partir da organização, em ordem crescente, das alturas totais das árvores, separadas em classes com amplitude de $1 \mathrm{~m}$ e, em seguida, elaborando uma matriz X de dados de alturas totais, em que cada variável $\mathrm{X}_{\mathrm{ij}}$ representa a altura total da $i$-ésima árvore classificada na $j$-ésima classe de altura total. A partir daí, utilizam-se análises de Cluster e discriminante, para avaliar a existência de grupos distintos de classes de altura total e a ratificação da formação destes grupos, respectivamente.

Calegario et al.(1994) descreveram a estratificação florestal a partir do teste não paramétrico Quiquadrado e determinaram a existência de grupos de dados de altura estatisticamente homogêneos, estabelecendo limites inferiores e superiores para classes definidas de estratos.

Péllico Netto \& Sanquetta (1996) apresentam um método para estratificação de florestas plantadas e naturais pelo qual se determina o número de estratos, utilizando-se a variável 'volume por unidade de área'.

De uma forma mais simples, Longhi et al. (2000) registraram a posição sociológica de cada árvore, considerando três estratos: inferior (3); médio (2); e superior (1). Os estratos foram separados visualmente por um membro de sua equipe, apresentando amplitude variável que dependia da altura máxima dos indivíduos presentes na parcela e na sua volta.

\section{REGENERAÇÃO NATURAL, POSIÇÃO SOCIOLÓGICA E VALOR DE IMPORTÂNCIA AMPLIADO}

Dentre os indicadores da estrutura vertical, três costumam ser considerados: a regeneração natural, a posição sociológica e o Valor de Importância Ampliado (Finol, 1971).

A regeneração natural representa o indivíduo jovem na floresta. Segundo Amo Rodríguez \& GómezPompa (1976), este é o estágio intermediário entre a plântula e o estado adulto vegetativo/reprodutivo, fundamental para a manutenção do equilíbrio da floresta, já que o fracasso dos processos adaptativos, nesse período, pode eliminar a espécie do local.

Para Scariot \& Reis,

[...] a regeneração natural é um processo que trata do desenvolvimento e reconstrução das comunidades naturais. Esse processo, em florestas tropicais que sofrem distúrbios naturais ou antrópicos, depende de fontes autogênicas e alogênicas. As fontes autogênicas são representadas pela expressão do banco de sementes do local que sofreu tal distúrbio e as alogênicas, pela expressão da chuva de sementes que chega nesse local. (Scariot \& Reis, 2010, p. 55).

De acordo com Hosokawa et al. (2008), a regeneração natural constitui importante indicador para a compreensão da capacidade de disseminação das espécies e do momento inicial de sua dinâmica na ocupação do ambiente. Em uma floresta, a organização estrutural (horizontal e vertical) e a distribuição diamétrica dependem de como as espécies se comportam neste momento inicial.

A regeneração pode ser avaliada por meio da frequência, da densidade e das categorias de tamanho (indivíduos são avaliados por classes de tamanho), sendo considerado que quanto maior for o indivíduo, maior também será sua possibilidade de permanecer na área (Longhi et al., 2000).

A estrutura sociológica e o valor de importância ampliado informam acerca da composição florística dos vários estratos da floresta, no sentido vertical, e do papel que desempenham as diferentes espécies em cada um dos estratos (Lamprecht, 1990; Hosokawa et al., 2008). 
Quadro 5. Parâmetros da Estrutura Vertical, Posição sociológica, Regeneração Natural e Valor de Importância Ampliado aplicados aos estudos fitossociológicos em comunidades vegetais.

Chart 5. Parameters of the vertical structure, sociological position, natural regeneration and Value of Expanded Importance applied to phytosociological studies in plant communities.

\begin{tabular}{|c|c|}
\hline $\begin{array}{l}\text { Estrato Vertical } \\
\text { Estrato Inferior: } h_{j}<(\bar{h}-1 . S) \\
\text { Estrato Médio: }(\bar{h}-1 . S) \leq h_{j}<(\bar{h}+1 . S) \\
\text { Estrato Superior: } h_{j} \leq(\bar{h}+1 . S)\end{array}$ & $\begin{array}{l}\bar{h}=\text { média das alturas dos indivíduos amostrados; } \\
\mathrm{S}=\text { desvio padrão das alturas totais }(\mathrm{h} \mathrm{j}) ; \\
\mathrm{h}_{\mathrm{j}}=\text { altura total da j-ésima árvore individual. }\end{array}$ \\
\hline $\begin{array}{l}\text { Posição Sociológica } \\
V F_{i j}=V F_{j} n_{i j} \\
V F_{j}=\frac{N_{j}}{N} \times 100 \\
P S A_{i}=\sum_{i=1}^{m} V F_{j} n_{i j} \\
P S R_{i}=\frac{P S A_{i}}{\sum_{i=1}^{S} P S A_{i}} \times 100\end{array}$ & $\begin{array}{l}\mathrm{VF}_{\mathrm{ij}}=\text { valor fitossociológico da i-ésima espécie no j-ésimo estrato; } \\
\mathrm{VF}_{\mathrm{j}}=\text { valor fitossociológico simplificado do j-ésimo estrato; } \\
\mathrm{n}_{\mathrm{ij}}=\text { número de indivíduos de i-ésima espécie no j-ésimo estrato; } \\
\mathrm{N}_{\mathrm{j}}=\text { número de indivíduos no j-ésimo estrato; } \\
\mathrm{N}=\text { número total de indivíduos de todas as espécies em todos os } \\
\text { estratos; } \\
\text { PSA }_{\mathrm{i}}=\text { posição sociológica absoluta da i-ésima espécie; } \\
\mathrm{PSR}_{\mathrm{i}}=\text { POS (\%) = posição sociológica relativa (\%) da i-ésima espécie; } \\
\mathrm{S}=\text { número de espécies; } \\
\mathrm{m}=\text { número de estratos amostrados. }\end{array}$ \\
\hline $\begin{array}{l}\text { Regeneração Natural } \\
\qquad A T_{i}=\sum_{j=1}^{J} n_{i j}\left(\frac{N_{j}}{N}\right) \\
C R T_{i}=\frac{C A T_{i}}{\sum_{i=1}^{S} C A T_{i}} \times 100 \\
R N R_{i}=\frac{F R_{i}+D R_{i}+C R T_{i}}{3}\end{array}$ & $\begin{array}{l}\mathrm{CAT}_{\mathrm{i}}=\text { classe absoluta de tamanho da regeneração da i-ésima espécie; } \\
\mathrm{CRT}_{\mathrm{i}}=\text { classe relativa de tamanho da regeneração da i-ésima espécie; } \\
\mathrm{n}_{\mathrm{ij}}=\text { número de indivíduos da i-ésima espécie na j-ésima classe de } \\
\text { tamanho; } \\
\mathrm{N}_{\mathrm{j}}=\text { número total de indivíduos na j-ésima classe de tamanho; } \\
\mathrm{N}=\text { número total de indivíduos da regeneração natural em todas as } \\
\text { classes de tamanho; } \\
\mathrm{RNR}_{\mathrm{i}}=\text { regeneração natural relativa da i-ésima espécie; } \\
\mathrm{FR}_{\mathrm{i}}=\text { frequência relativa da regeneração natural da i-ésima espécie; } \\
\mathrm{R}_{\mathrm{i}}=\text { densidade relativa da regeneração natural da i-ésima espécie. }\end{array}$ \\
\hline $\begin{array}{l}\text { Valor de Importância Ampliado } \\
V I A_{i}=D R_{i}+F R_{i}+D o R_{i}+P S R_{i}+R N R ; \\
V I A(\%)=\frac{V I A_{i}}{5}\end{array}$ & VIA = Valor de Importância Ampliado. \\
\hline
\end{tabular}

Fonte: Hosokawa et al. (2008).

No Quadro 5 estão apresentadas as fórmulas para os cálculos dos parâmetros fitossociológicos da estrutura vertical.

\section{CONSIDERAÇÕES FINAIS}

As comunidades vegetais representam tipologias reconhecidas por sua composição florística e sua estrutura, associadas às suas relações interespecíficas com o meio ambiente.

Por meio da Fitossociologia, torna-se possível reconhecer espécies ocorrentes em uma comunidade, que expressam capacidades de indicadoras (espécies comuns, raras e acompanhantes). Estas informações consubstanciam estratégias de manejo que podem garantir a conservação de guildas relevantes para o funcionamento de ecossistemas terrestres. Tal conhecimento constitui uma das ferramentas contemporâneas para o estudo científico da vegetação natural e da paisagem cultural, com aplicações no ordenamento, no planejamento e na gestão territorial, em geral, e do espaço florestal, em particular (Capelo, 2003).

Arruda \& Daniel (2007) afirmam que os estudos fitossociológicos de uma floresta representam o passo inicial para o seu conhecimento, pois, quando 
associados à sua dinâmica, pode-se construir uma base teórica para subsidiar a preservação e o uso de recursos da flora, a conservação de ecossistemas similares e a recuperação de áreas ou fragmentos florestais degradados, contribuindo substancialmente para seu manejo.

Esses estudos são, portanto, condição essencial para que se possam estabelecer atualizações das divisões fitogeográficas (Silva \& Leitão Filho, 1982); elaborar planos e ações de recuperação de áreas degradadas (Araújo et al., 2006; Jacobi et al., 2008; Pinheiro et al., 2009); avaliar a dinâmica e a evolução de fragmentos florestais (Melo \& Mantovani, 1994; Ivanauskas \& Rodrigues, 2000; Bertani et al., 2001); estabelecer práticas de manejo e condução de agroecossistemas (Magalhães \& Freitas, 2004; Pinheiro, 2007; Lobão \& Valeri, 2009); propor tratos silviculturais em plantios de essências florestais (Aubert \& Oliveira Filho, 1994; Camargo, 1998; Saporetti Junior et al., 2003; Mochiutti et al., 2008); adotar estratégias para a conservação da biodiversidade (Peixoto \& Gentry, 1990; Lima et al., 2006; Oliveira-Filho et al., 2008); atualizar planos de manejo (Rosot, 1982), e subsidiar programas de recuperação ambiental em empreendimentos (Peixoto et al., 1995; Meira Neto et al., 1997).

Mesmo assim, apesar dos esforços despendidos por inúmeros cientistas, as pesquisas conduzidas para estudos fitossociológicos no Brasil ainda são consideradas insuficientes. Um maior investimento nestes estudos permitirá um avanço mais consistente para as ações de conservação e uso da natureza.

\section{STATUS DA SUBMISSÃO}

Recebido: 09/10/2011

Aceito: $12 / 09 / 2012$

Publicado: 31/12/2012

\section{AUTOR(ES) PARA CORRESPONDÊNCIA}

\section{Welington Kiffer de Freitas}

Secretaria de Ciência e Tecnologia do Estado do Rio de Janeiro - SECT, Fundação de Apoio à Escola Técnica do Estado do Rio de Janeiro - FAETEC, Rio de Janeiro, RJ, Brasil e-mail:wkfreitas@gmail.com

\section{Luís Mauro Sampaio Magalhães}

Departamento de Ciências Ambientais, Instituto de Florestas, UFRRJ, Km 07 Rodovia BR 465, Seropédica, RJ, CEP 23890-000, Brasil, e-mail:1.mauro@terra.com.br

\section{REFERENNCIAS}

Amo Rodríguez S, Gómez-Pompa A. Crecimento de estados juveniles de plantas em Selva Tropical Alta Perennifolia. In: Gómez-Pompa A, Vázquez-Yanees C, Amo Rodríguez S. Regeneration de Selvas. México: Continental; 1976.

Araújo FS, Martins SV, Meira Neto JAA, LaniJLL, Pires IE. Estrutura da vegetação arbustivo-arbórea colonizadora de uma área degradada por mineração de caulim, Brás Pires, MG. Revista Árvore 2006; 30(1): 107-116. http:// dx.doi.org/10.1590/S0100-67622006000100013

Ariza FJA. El método fitosociológico. España: Universidad de Murcia; 2010. Geobotánica Tema 13.

Arruda L, Daniel O. Florística e diversidade em um fragmento de floresta estacional semidecidual aluvial em Dourados, MS. Revista Floresta 2007; 37(2):187-199.

Aubert E, Oliveira Filho AT. Análise multivariada da estrutura fitossociológica do sub-bosque de plantios experimentais de Eucalyptus spp. e Pinus spp. em Lavras, MG. Revista Árvore 1994; 18(3):194-214.

Barros PLC. Estudo das distribuições diamétricas da floresta do Planalto Tapajós - Pará [dissertação]. Curitiba: Universidade Federal do Paraná; 1980.

Batista JLF, Schilling AC. Um Algoritmo Matricial para Construção da "Curva de Acumulação de Espécies" METRVM. [cited 2010 jun. 05]. Available from: http:// lmq.esalq.usp.br/METRVM.

Bertani DF, Rodrigues RR, Batista JLF, Shepherd G. Análise temporal da heterogeneidade florística e estrutural em uma floresta ribeirinha. Revista Brasileira de Botânica 2001; 24(1): 11-23. http://dx.doi. org/10.1590/S0100-84042001000100002

Borém RAT, Ramos DP. Fitossociologia do estrato arbóreo em uma toposseqüência alterada de mata Atlântica, no município de Silva Jardim - RJ. Revista Árvore 2001; 25(1): 131-140.

Braun-Blanquet J. Fitosociologia: bases para el estudio de las comunidades vegetales. 3. ed. Madrid: Aum. Blume; 1979.

Brito A, Ferreira MZ, Mello JM, Scolforo JRS, Oliveira AD, Acewrbi FW. Comparação entre os métodos de quadrantes e PRODAN para análises florística, fitossociológica e volumétrica. Revista Cerne 2007; 13(4): 399-405. 
Brower JE, Zar JH. Field \& laboratory methods for general ecology. 2nd ed. Iowa: Wm. C. Brown Publishers; 1984.

Calegario N, Scolforo JRS, Souza AL. Estratificação em alturas para floresta natural heterogênea: uma proposta metodológica. Revista Cerne 1994; 1(1): 58-63.

Camargo SL. Composição e estrutura fitossociológica da vegetação natural sob plantio de Eucalyptus grandis W. Hill ex Maiden no município de Dionísio-MG [dissertação]. Belo Horizonte: Universidade Federal de Minas Gerais; 1998.

Campelo EFC. Sucessão vegetal na recuperação de áreas degradadas. In: Dias LF, Melo JWV, editores. Recuperação de áreas degradadas. Viçosa: SOBRADE, UFV; 1998.

Capelo J. Conceitos e métodos da Fitossociologia: Formulação contemporânea e métodos numéricos de análise da vegetação. Oeiras: Estação Florestal Nacional, Sociedade Portuguesa de Ciências Florestais; 2003.

Cavassan O, Cesar O, Martins FR. Fitossociologia da vegetação arbórea da reserva estadual de Bauru, Estado de São Paulo. Revista Brasileira de Botânica 1984; 7(2): 91-106.

Cullen Junior L, Rudran R, Valladares-Padua C. Métodos de estudo em biologia da conservação e manejo da vida silvestre. Curitiba: Ed. da UFPR; Fundação O Boticário de Proteção à Natureza; 2004.

Daniel O. Subsidios al uso del índice de diversidad de Shannon. In: Anais do I Congreso Latinoamericano IUFRO; 1998; Valdivia. Valdivia: IUFRO. [CD ROM].

Dias AC. Composição florística, fitossociologia, diversidade de espécies e comparação de métodos de amostragem na Floresta Ombrófila Densa do Parque Estadual Carlos Botelho/Sp-Brasil [tese]. Piracicaba: Escola Superior de Agricultura "Luiz de Queiroz", Universidade de São Paulo; 2005.

Dias SC. Planejando estudos de diversidade e riqueza: uma abordagem para estudantes de graduação. Acta Scientiarum 2004; 26(4): 373-379. http://dx.doi. org/10.4025/actascibiolsci.v26i4.1511

Durigan G. Métodos para análise de vegetação arbórea. In: Cullen Junior L, Rudran R, Valladares-Pádua C, organizadores. Métodos de Estudos em Biologia da Conservação e Manejo da Vida Silvestre. Curitiba: UFPR; Fundação Boticário de Proteção à Natureza; 2003.

Durigan G. Estrutura e diversidade de florestas tropicais. In: Martins SV, organizadores. Ecologia de Florestas Tropicais do Brasil. Viçosa: Editora UFV; 2009.

Durigan G, Leitão Filho HF. Florística e fitossociologia de matas ciliares do oeste paulista. Revista do Instituto Florestal, 1995; 2(7): 197-239.

Faria JA. Atividade florestal no contexto da fumicultura: oportunidade de desenvolvimento regional, diversificação, geração de emprego e renda [tese]. Santa Maria: Universidade Federal de Santa Maria; 2010.

Farias CA, Soares CPB, Souza AL, Leite HG. Comparação de métodos de amostragem para análise estrutural de florestas inequiâneas. Revista Árvore 2002; 26(5): 541-548. http://dx.doi.org/10.1590/ S0100-67622002000500003

Felfili JM, Eisenlohr PV, Melo MMRF, Andrade LA, Meira Neto JAA. Fitossociologia no Brasil - Volume 1: Métodos e estudos de casos. UFV, 2011.

Fernandes AG. Fitogeografia Brasileira. 3. ed. Fortaleza: Edições UFC; 2000.

Fernandes AG. Conexões Florísticas do Brasil. Fortaleza: BNB; 2003.

Finol H. Nuevos parâmetros a considerar-se en el análises estructural de las selvas virgenes tropicales. Revista Forestal Venezoelana 1971; 21(14): 24-42.

Gauch Junior HG. Multivariate Analysis in Community Ecology. Cambridge: Cambridge University Press; 1982. http://dx.doi.org/10.1017/CBO9780511623332

Gorenstein MR. Métodos de amostragem no levantamento da comunidade arbórea em Floresta Estacional Semidecidual [dissertação]. Piracicaba: Escola Superior de Agricultura "Luiz de Queiroz", Universidade de São Paulo; 2002.

Gotelli NJ. Ecologia. 4. ed. Londrina: Editora Planta; 2009.

Gotelli NJ, Ellison AM. Princípios de estatística em ecologia. Porto Alegre: Editora Artmed; 2011.

Guapyassú MS. Caracterização fitossociológica de três fases sucessionais de uma Floresta Ombrófila Densa Submontana, Morretes - Paraná [dissertação]. Curitiba: Universidade Federal do Paraná; 1994.

Guedes-Bruni RR, Pessoa SVA, Kurtz BC. Florística e estrutura do componente arbustivo-arbóreo de um trecho preservado de floresta montana na Reserva Ecológica de Macaé de Cima. In: Lima HC \& GuedesBruni RR, editores. Serra de Macaé de Cima: Diversidade florística e conservação em Mata Atlântica. Rio de Janeiro: Jardim Botânico do Rio de Janeiro; 1997. v. 1.

Gurevitch J, Scheiner SM, Fox GA. Ecologia vegetal. 2. ed. Porto Alegre: ed. Artmed; 2009.

Hack C, Longhi SJ, Boligon AA, Murari AB, Pauleski DT. Análise fitossociológica de um fragmento de floresta estacional decidual no município de Jaguari, RS. Revista Ciência Rural 2005; 35(5): 1083-1091. http:// dx.doi.org/10.1590/S0103-84782005000500015

Herrera HAR, Rosot NC, Rosot MAD, Oliveira YMM. Análise Florística e Fitossociológica do Componente Arbóreo da Floresta Ombrófila Mista Presente na Reserva Florestal EMBRAPA/EPAGRI, Caçador, SC - Brasil. Revista Floresta 2009; 39(3): 485-500. 
Hosokawa RT, Moura JB, Cunha US. Introdução ao manejo e economia de florestas. Curitiba: Ed UFPR; 2008.

Instituto Brasileiro de Geografia e Estatística - IBGE. Manual técnico da vegetação brasileira. Rio de Janeiro: IBGE; 1992. (Série Manuais Técnicos em Geociências n 1).

Iserhagen I, Menezes-Silva S, Galvão F. A fitossociologia florestal no Paraná: listagem bibliográfica comentada. [cited 2011 mai. 20]. Available from: http://www.ipef. $\mathrm{br} /$ servicos/teses/arquivos/isernhagen,i.pdf.

Ivanauskas NM, Rodrigues RR. Similaridade Florística entre Áreas de Floresta Atlântica no Estado de São Paulo. Brazilian Journal of Ecology 2000; 4:1-2: 71-81.

Jacobi CM, Carmo FF, Vincent RC. Estudo fitossociológico de uma comunidade vegetal sobre canga como subsídio para a reabilitação de áreas mineradas no Quadrilátero Ferrífero, MG. Revista Árvore 2008; 32(2): 345-353. http://dx.doi.org/10.1590/ S0100-67622008000200017

Kageyama PY, Gandara FB. Recuperação de áreas degradadas. In: Rodrigues RR, Leitão Filho HF. Matas ciliares: conservação e recuperação. São Paulo: EDUSPFAPESP; 2004.

Krebs J. Ecological methodology. New York: Harper \& Row; 1989.

Lamprecht H. Silvicultura nos trópicos: ecossistemas florestais e respectivas espécies arbóreas - possibilidades e métodos de aproveitamento sustentado. Rossdorf: República Federal da Alemanha: Dt. Ges. Für Techn. Zusammenarbeit; 1990.

Lima HC, Pessoa SVA, Guedes-Bruni RR, Moraes LFD, Granzotto SV, Iwamoto $S$ et al. Caracterização Fisionômico-Florística e Mapeamento da Vegetação da Reserva Biológica de Poço das Antas, Silva Jardim, Rio de Janeiro, Brasil. Rodriguesia 2006; 57(3): 369-389.

Lobão DE, Valeri SV. Sistema cacau-cabruca: conservação de espécies arbóreas da floresta atlântica. Agrotrópica 2009; 21(1): 43-54.

Longhi SJ. Aspectos fitossociológicos dos “capões” na região de Carovi e Tupantuba, em Santiago, RS. Revista Ciência Florestal 1991; 1(1): 22-39.

Longhi SJ, Selle GL, Ragagnin LIM, Damiani JE. Composição florística e fitossociológica de um "capão" de Podocarpus Lambertii Klotz. Revista Ciência Florestal 1992; 2(1): 9-26.

Longhi SJ, Araujo MA, Kelling MB, Hoppe JM, Müller I, Borso GA. Aspectos fitossociológicos de fragmento de Floresta Estacional Decidual, Santa Maria, RS. Revista Ciência Florestal 2000; 10(2): 59-74.

Lorenzini AR. Fitossociologia e aspectos dendrológicos da goiabeira-serrana na Bacia Superior do Rio Uruguai [dissertação]. Lages: Universidade do Estado de Santa Catarina; 2006.
Lousã M, Monteiro A, Espírito Santo D, Sousa E, Costa JC. Módulo de botânica: Manual de teóricas e práticas. Instituto Superior de Agronomia, Universidade Técnica de Lisboa; 2007. 144 p. [cited 2011 mar. 8]. Available from: http://www.isa.utl.pt/files/pub/ensino/cdocente/ MANUAL_BOTANICA_.pdf.

Machado ELM, Oliveira-Filho AT, Carvalho WAC, Souza JS, Borém RAT, Botezelli L. Análise comparativa da estrutura e flora do compartimento arbóreo-arbustivo de um remanescente florestal na Fazenda Beira Lago, Lavras, MG. Revista Árvore 2004; 28(4): 499-516. http:// dx.doi.org/10.1590/S0100-67622004000400005

Magalhães LMS, Freitas WK. Fragmentos florestais em pequenas propriedades rurais: bases para o seu manejo e conservação. In: Seminário Agricultura migratória na região serrana do Rio de Janeiro; 2006; Bom Jardim. Seropédica: EMBRAPA; 2004. p. 32-39. (Cadernos de Ecologia).

Mantovani A, Reis A, Anjos A, Siminski A, Fantini AC, Puchalski A et al. Inventário e manejo florestal. Amostragem, caracterização de estádios sucessionais na vegetação catarinense e manejo do palmiteiro (Euterpe edulis) em regime de rendimento sustentável. Florianópolis: Núcleo de Pesquisas em Florestas Tropicais - NPFT; 2005.

Martins FR. Estrutura de uma floresta mesófila. Campinas: Ed. UNICAMP; 1991.

Martins FR, Santos FAM. Técnicas usuais de estimativa da biodiversidade. In: Anais do I Congresso Brasileiro de Conservação e Manejo da Biodiversidade; 1999; Ribeirão Preto. Revista Holos. Ribeirão Preto: Universidade Estadual Paulista, 1999, 1: 236-267.

Matos RMB, Silva EMR, Berbara RLL. Biodiversidade e Índices. Seropédica: Embrapa Agrobiologia, 1999. (Embrapa-CNPAB, Documentos, 107).

Matteucci SD, Colma A. Metodologia para el estudio de la vegetación. Washington: The General Secretarial of The Organization of American States; 1982. (Série Biologia - Monografia, n. 22).

Medeiros DA. Métodos de amostragem no levantamento da diversidade arbórea do Cerradão da Estação Ecológica de Assis [dissertação]. Piracicaba: Escola Superior de Agricultura Luiz de Queiroz, Universidade de São Paulo; 2004.

Meira Neto JAA, Souza AL, Silva AF, Paula AC. Estrutura de uma floresta estacional semidecidual insular em área de influência da Usina Hidrelétrica de Pilar, Ponte Nova, Zona da Mata de Minas Gerais. Revista Árvore 1997; 21: 493-500.

Melo AS. O que ganhamos 'confundindo' riqueza de espécies e equabilidade em um índice de diversidade? Biota Neotropica 2008; 8(3). [cited 2011 mar. 15]. Available from: http://www.biotaneotropica.org.br/ v8n3/pt/abstract?point-of-view+bn00108032008. 
Melo MMRF, Mantovani W. Composição florística e estrutura de trecho de mata Atlântica de encosta na ilha do Cardoso (Cananéia, SP - Brasil). Boletim do Instituto de Botânica 1994; 9: 107-158.

Mochiutti S, Higa AR, Simon AA. Fitossociologia dos estratos arbóreos e da regeneração natural em um povoamento de acácia-negra (Acacia mearnsii Wild.) $\mathrm{Na}$ região da Floresta Estacional Semidecidual do Rio Grande do Sul. Ciência Florestal 2008; 18(2): 68-95.

Montoya-Maquin JM. El acuerdo Yangambi (1956) como base para una nomenclatura de tipos de vegetacion en el trópico americano. Turrialba 1966; 16(2): 169-180.

Moraes e Silva VS. Manejo de florestas nativas: planejamento, implantação e monitoramento. Cuiabá: UFMT; 2006.

Moscovich FA. Dinâmica de crescimento de uma Floresta Ombrófila Mista em Nova Prata, RS [tese]. Santa Maria: Universidade Federal de Santa Maria; 2006.

Moscovich FA, Brena DA, Longhi SJ. Comparação de diferentes métodos de amostragem, de área fixa e variável, em uma floresta de Araucaria angustifolia. Ciência Florestal 1999; 9(1): 173-191.

Mueller-Dombois D, Ellenberg H. Aims and methods of vegetation ecology. New York: John Wiley \& Sons; 1974.

Narvaes IS, Longhi SJ, Brena DA. Florística e classificação da regeneração natural em Floresta Ombrófila Mista na Floresta Nacional de São Francisco de Paula, RS. Ciência Florestal 2008; 18: 233-245.

Odum EP. Ecologia. Rio de Janeiro: Editora Guanabara Koogan, 1988.

Oliveira AA. Diversidade, estrutura e dinâmica do componente arbóreo de uma floresta de terra firme de Manaus, Amazonas [tese]. São Paulo: Universidade de São Paulo; 1997.

Oliveira-Filho AT. Composição florística e estrutura comunitária da floresta de galeria do córrego da Paciência, Cuiabá (MT). Acta Botanica Brasilica, 1989; 31(1): 91-112.

Oliveira-Filho AT, Van Den Berg E, Machado ELM, Pifano DS, Valente ASM, Martins JC, Silva CPC. Espécies de ocorrência exclusiva do Domínio do Cerrado. In: Oliveira-Filho AT, Scolforo JRS, organizadres. Inventário Florestal de Minas Gerais: Espécies arbóreas da flora nativa. Lavras: Editora UFLA; 2008.

Padoin V. Diretrizes para desbaste de Pinus taeda L.em função da altura dominante [disssertação]. Santa Maria: Universidade Federal de Santa Maria; 2007.

Peixoto AL, Gentry A. Diversidade e composição florística da mata de tabuleiros na Reserva Florestal de Linhares (Espírito Santo, Brasil). Revista Brasileira de Botânica 1990; 13: 19-25.
Peixoto AL, Rosa MMT, Barbosa MRV, Rodrigues HC. Composição florística da Represa de Ribeirão das Lajes. Revista da Universidade Rural. Série Ciências da Vida; 1995; 17(1): 51-74.

Péllico Netto S, Brena DA. Obtenção da densidade de povoamentos no método de amostragem de Strand. Revista Cerne 1996; 2(2): 81-90.

Péllico Netto S, Brena DA . Inventário Florestal. Curitiba: Editorado pelos autores, 1997.

Péllico Netto S, Sanquetta CR. Determinação do número de estratos em estratificação volumétrica de florestas naturais e plantadas. Floresta 1996; 24(1): 4958.

Pereira Sobrinho JC. Estudo Comparativo da Eficiência de Métodos de Parcelas com Área Fixa e Métodos de Distância em Inventário Florestal. Brasil Florestal 2003; 77(23): 51-60.

Pereira-Silva EFL, Santos J E, Kageyama PY, Hardt E. Florística e fitossociologia dos estratos arbustivo e arbóreo de um remanescente de cerradão em uma Unidade de Conservação do Estado de São Paulo. Revista Brasileira de Botânica 2004; 27(3): 533-544. http://dx.doi.org/10.1590/S0100-84042004000300013

Pielou EC. Mathematical Ecology. New York: John Wiley \& Sons; 1977

Pinheiro MAS. Fitossociologia de Áreas Enriquecidas com o Palmiteiro Euterpe edulis (Martius) em Paisagens Alteradas da Mata Atlântica [dissertação]. Seropédica: Universidade Fedetal Rural do Rio de Janeiro, 2007.

Pinheiro RC, Corrêa RS, Silveira IM, Jesus RS, Jorge RRA. Análise fitossociológica do estrato arbóreo de uma cascalheira revegetada no Distrito Federal. Revista Cerne 2009; 15(2): 205-214.

Pinto-Coelho RM. Fundamentos em Ecologia. Porto Alegre: ARTMED Editora; 2000.

Porto ML. Comunidades vegetais e fitossociologia: fundamentos para avaliação e manejo de ecossistemas. Porto Alegre: Ed. da UFRGS; 2008.

Ribeiro SB. Classificação e ordenação da comunidade arbórea da Floresta Ombrófila Mista da FLONA de São Francisco de Paula, RS [tese]. Santa Maria: Universidade Federal de Santa Maria; 2004.

Rodrigues WA, Pires JM. Inventário fitossociológico. In: Anais do Encontro sobre Inventários Florísticos na Amazônia; 1988; Manaus. Manaus; 1988.

Rodrigues RR. Análise estrutural das formações ripárias. In: Anais do I Simpósio Sobre Mata Ciliar; 1989; São Paulo. Campinas: Fundação Cargil, 1989. p. 99-119.

Rodrigues RR, Martins SV, Gandolfi S, editors. High diversity forest restoration in degraded areas: methods and projects in Brazil. New York: Nova Science Publisher; 2007. 
Rodrigues WC. DivEs - Diversidade de Espécies - Guia do Usuário. Seropédica: Entomologistas do Brasil; 2007. 9 p. [cited 2011 mar. 2]. Available from: http://www.ebras. bio.br/dives/.

Rosot NC, Amaral-Machado S, Figueiredo Filho A. Análise estrutural de uma floresta tropical como subsídio básico para elaboração de um plano de manejo florestal. In: Anais do Congresso Nacional Sobre Essências Nativas; 1982; São Paulo. São Paulo: Instituto Florestal; 1982. v. 16 A, pt. 1. p. 468-490.

Sampaio EVSB, Salcedo IH, Kauffman JB. Effect of different fire severities on coppicing of caatinga vegetation in Serra Talhada, PE, Brazil. Biotropica 1993; 25(4): 452-460. http://dx.doi. org/10.2307/2388868

Sanquetta CR. Análise da estrutura vertical de florestas através do diagrama h-M. Ciência Florestal 1995; 5(1): 55-68.

Santos JHS, Ferreira RLC, Silva JAA, Souza AL, Santos ES, Meunier IMJ. Distinção de grupos ecológicos de espécies florestais por meio de técnicas multivariadas. Revista Árvore 2004; 28(3): 387-396. http://dx.doi. org/10.1590/S0100-67622004000300010

Santos VK. Uma generalização da distribuição do índice de diversidade generalizada por Good com aplicação em Ciências Agrárias [monografia]. Recife: Universidade Fedetal Rural de Pernambuco; 2009.

Saporetti Junior AW, Meira Neto JAA, Almado R. Fitossociologia de sub-bosque de cerrado em talhão de Eucalyptus grandis W. Hill ex Maiden no município de Bom Despacho-MG. Revista Árvore 2003; 27(6): 905-910. http://dx.doi.org/10.1590/ S0100-67622003000300020

Scariot EC, Reis A. Riqueza e estrutura florística de corredores ciliares em regeneração natural no planalto norte catarinense, sul do Brasil. Perspectiva 2010; 34(125): 53-65.

Schilling AC, Batista JLF. Efeito do tamanho da amostra sobre a curva de acumulação de espécies arbóreas em florestas tropicais. In: Caderno de Resumos da 51 Reunião Anual da Região Brasileira da Sociedade
Internacional de Biometria; 2006; Botucatu. Botucatu: RBRAS; 2006.

Schilling AC, Batista JLF. Curva de acumulação de espécies e suficiência amostral em florestas tropicais. Revista Brasileira de Botânica 2008; 31(1):179-187. http://dx.doi.org/10.1590/S0100-84042008000100016

Schilling AC, Talora DC. Algumas implicações do uso de Bootstrap na construção de intervalos de confiança empíricos para a curva espécie-área. In: Anais da 49. Reunião Anual da Região Brasileira da Sociedade Internacional de Biometria; 2004; Uberlândia. Uberlândia; 2004. p. 460-464.

Schneider PR, Finger CAG. Manejo sustentado de floresta inequiâneas heterogêneas. Santa Maria: UFMS; 2000.

Senra LC. Composiçãoflorísticae estruturafitossociológica de um fragmento florestal da fazenda rancho fundo, na Zona da Mata - Viçosa, MG [dissertação]. Viçosa: Universidade Federal de Viçosa; 2000.

Silva AF, Leitão Filho HF. Composição florística e estrutura de um trecho da mata atlântica de encosta no município de Ubatuba (São Paulo, Brasil). Revista Brasileira de Botânica 1982; 5(1-2): 43-52.

Souza AL. Análise multivariada para manejo de florestas naturais: alternativas de produção sustentada de madeiras para serraria [tese]. Curitiba: Universidade Federal do Parana, 1989

Souza AL, Leite HG. Regulação da produção em florestas inequiâneas. Viçosa: UFV, 1993.

Souza DR, Souza AL, Gama JRV, Leite HG. Emprego de análise multivariada para estratificação vertical de florestas inequiâneas. Revista Árvore 2003; 27(1): 59-63. http://dx.doi.org/10.1590/S0100-67622003000100008

Trimer NFC, organizador. Ciência, História e Arte: Obras Raras e Especiais do Instituto de Biociências da Universidade de São Paulo. São Paulo: EDUSP; 2010.

Vuono YS. Inventário fitossociológico. In: Sylvestre LS, Rosa MMT, organizadores. Manual metodológico para estudos botânicos na Mata Atlântica. Seropédica: EDUR; 2002. 